\title{
Reading performance with various lamps in age-related macular degeneration
}

F Eperjesi, C Maiz-Fernandez and HE Bartlett

Ophthalmic Research Group, School of Life and Health Sciences, Aston University, Birmingham, B4 7ET, UK.

\begin{abstract}
The purpose of this study was to determine if there was an objective difference in reading between four commonly available lamps, of varying spectral radiance, for 13 subjects with age-related maculopathy (ARM) or non-exudative age-related macular degeneration (AMD-logMAR visual acuity range 0.04 to 0.68 ). At a constant illuminance of 2000 lux, there was no interaction between ARM and AMD subgroups and no statistically significant difference between the lamps: standard (clear envelope) incandescent, daylight simulation (blue tint envelope) incandescent, compact fluorescent and halogen incandescent, for any reading outcome measure. Threshold print size $p=0.67$, critical print size $p=0.74$, acuity reserve $p=0.84$ and mean reading rate $p=0.78$. For lamps typically used in low vision rehabilitation, there is unlikely to be a clinically significant effect of spectral radiance on reading for people with ARM or non-exudative AMD.
\end{abstract}




\section{Introduction}

Individuals with age-related macular degeneration (AMD) often complain of reading difficulties (Elliott et al., 1997; Mangione et al., 1998; De l'Aune et al., 2000; Hazel et al., 2000). There is general agreement amongst researchers that many people with low vision, especially when due to AMD, demonstrate improvement in visual function with optimum levels of localised lighting. For example, increased reading performance (Sloan, 1969; Kitchin, 1981; LaGrow, 1986; Eldred, 1992; Brown and Kitchin, 1983; Bowers et al., 2001; Fosse and Valberg, 2004; Haymes and Lee, 2006) and improved visual acuity (VA) and contrast sensitivity (CS - Silver et al., 1978; Julian 1984; Cohen and Rosenthal, 1988; Haymes and Lee, 2006). Based on this evidence, eye care practitioners commonly recommend the use of a lamp placed near the task to people with low vision; this is often referred to as local or localised lighting. The intention is to achieve more efficient and comfortable performance of near vision tasks through the use of supplementary lighting.

Our clinical experience and that of others (Mehr and Freid, 1975; Fonda, 1981) suggests that low vision clinics usually have several different types of lamps available for demonstration purposes and that patients often ask which lamp is best for home use. Cullinan et al. (1979) reported that a 60W lamp improved home based VA up to levels found in a hospital clinic for $82 \%$ of their subjects while Gill and Silver (1982) recommended the use of a $60 \mathrm{~W}$ 'architectural spotlight' (Thorn Decorspot 80 producing 3800 lux positioned $40 \mathrm{~cm}$ from the plane of the task) when high illuminance is required. Collins (1987a) evaluated the performance of three lamps (standard incandescent-60W, daylight simulation incandescent-100W, and compact fluorescent-11W) on subjects with low vision due to various ocular pathologies and found no significant variation in VA. Interestingly, the observers preferred the daylight simulation incandescent and compact fluorescent lamps subjectively. However, this report was not peer reviewed and failed to provide details of the spectral radiance or the illuminance levels used and whether this was the same for each lamp type. Cohen and Rosenthal (1988) compared high and low contrast VA using daylight simulation incandescent and standard incandescent lamps on low vision patients with various ocular pathologies and a found statistically significant improvement with the daylight lamp for short-term tasks. However, the investigators also noted that the finding was unlikely to be of clinical significance. Soldatova (1990) used four light sources (incandescent, fluorescent, mercury arc and natrium) and measured VA, visual field, colour perception and photo-stress for normals and subjects with macular dystrophy. Spectral composition had more of an influence on all the visual variables for the low vision group and the natrium lamp (yellow light) produced the best visual performance. The short wavelength light of the mercury arc and the fluorescent lamp decreased visual performance in the low vision group but had no effect on the control group. More recently, Haymes and Lee (2006) found only a small statistically significant effect on peak CS for subjects with various types of AMD when using a daylight simulation incandescent lamp.

The purpose of the current study was to determine if there was an objective difference in reading between four commonly available lamps, of varying spectral radiance, for 13 subjects with age-related maculopathy (ARM) or non-exudative AMD. We decided to study this low vision group for three reasons. Firstly, AMD is the most common cause of blind and partial sight registration in the UK (Evans, 1995) and is therefore a major public 
health concern. Secondly, research findings suggest that people with AMD often benefit from optimum localised lighting (Sloan, 1969; Kitchin, 1981; Eldred, 1992; Brown and Kitchin, 1983; Bowers et al., 2001; Fosse and Valberg, 2004; Haymes and Lee, 2006). Finally, although wavelength dependent lenticular scatter does not occur in normal young, elderly or cataractous eyes (Whitaker et al, 1993) we wondered if there was a relationship between spectral radiance and retinal scatter.

\section{Method}

\section{Subjects}

We designed the study as a prospective trial in a clinical practice setting. All participants engaged in an informed consent process and signed a written consent document before participating in the study, which was approved by Aston University Human Ethics Committee. Thirteen subjects (four males and nine females) all with ARM or non-exudative AMD (confirmed by an ophthalmologist) were recruited consecutively from a larger group of people that had enrolled in a longitudinal randomised controlled trial investigating the effects of nutritional supplements on visual function in AMD (Bartlett and Eperjesi, 2003). None of the participants was pseudophakic and all had crystalline lens opacities graded as one or less on the Lens Opacities Classification System (Chylack et al., 1988). None had undergone any form of ocular medical or surgical treatment, none were taking any prescribed medication that may have interfered with vision and none had any apparent cognitive deficits, although this was not tested psychometrically. All had English as their first language.

\section{Materials}

Four lamps were used in this study: standard (clear envelope) incandescent (SI), daylight simulation (blue tint envelope) incandescent (DI), compact cool white fluorescent (CF) and halogen incandescent (HI). A PhotoResearch PR-650 SpectraScan $\AA$ SpectraColorimeter (Photo Research ${ }^{\circledR}$, Inc., 9731 Topanga Canyon Place, Chatsworth, CA) was used to obtain spectral radiance curves (see figure 1), correlated colour temperature and chromaticity coordinates for each lamp by sampling the light reflected from a white matt surface at a constant illuminance of 2000 lux and these are presented in table 1.

Reading performance was evaluated using MNRead Acuity Charts (Lighthouse Low Vision products, 36-02 Northern Boulevard, Long Island City, NY). These are continuous text reading acuity charts specifically designed to be sensitive to visual factors (Legge et al., 1989; Ahn et al., 1995). The chart consists of a series of 19 simple sentences printed at progressively smaller sizes (logMAR 1.3 to -0.5 at the recommended viewing distance of $40 \mathrm{~cm}$ ). Each sentence contains 60 characters (including a space between each word and at the end of each line) printed as three lines with even left and right margins. Two cards, MNRead Acuity Charts 1 and 2 (black text on a white background with different words on each card) were used. Outcome measures were: threshold print size (TPS - corrected for errors, 0.01 logMAR per standard word or part thereof), critical print size (CPS minimum print size (logMAR) for maximum reading rate [reading rate when reading is not limited by print size]), log acuity reserve (AR - log critical print size minus log threshold print size [Whittaker and Lovie-Kitchin, 1993]) 
and mean reading rate (MRR - mean oral reading rate for print sizes $\geq$ CPS in correct words per minute). Reading performance using objectively and subjectively determined optimum levels of illuminance has been shown to be very similar (Bowers et al, 2001) and therefore we restricted out investigation to objective measures only.

A CA 810 Luxmeter (Chauvin Arnoux, 853 Plymouth Road, Slough) was used to position each lamp in order to produce an illuminance of 2000 lux in the plane of each MNRead Chart. Reading performance for a group of subjects with mainly non-exudative AMD has been shown to plateau at this level (Bowers et al., 2001).

\section{Procedure}

Each participant underwent subjective refraction of both eyes. Distance logMAR VA was measured under standard testing conditions using a logMAR chart, retroilluminated to a luminance of $130 \mathrm{cdm}^{-2}$ (Bailey and Lovie, 1976). Each letter seen was scored as -0.02 log units, with guessing encouraged. Near logMAR VA was measured at $40 \mathrm{~cm}$ with a Logarithmic Near Visual Acuity Chart (Precision Vision, 994 First Street, La Salle, IL) at a luminance of 250 lux generated by ceiling mounted fluorescent lamps. Each letter seen was scored as -0.02 log units, with guessing encouraged. Log contrast sensitivity (CS) was measured in the eye with the better VA with full refractive correction plus a working distance lens of +1.00DS in place, using a Pelli-Robson chart (mean screen luminance $85 \mathrm{cdm}^{-2}$ ) at $1 \mathrm{~m}$ and scored per letter. The eye with the poorer near logMAR VA was occluded while the other eye was fully corrected for any refractive error and a $40 \mathrm{~cm}$ reading distance, using full aperture trial lenses. Subjects were asked to read from one of the MNRead cards at $40 \mathrm{~cm}$ as rapidly as possible, using each lamp. Charts were placed on a copyholder angled to be parallel to the plane of each participants face. Participants started with print size equivalent to $1.0 \log M A R$ VA at $40 \mathrm{~cm}$ and read out loud until they could no longer identify any of the words in the next sentence, paused for more than 10 seconds or gave up, i.e. the threshold print size had been reached. They were encouraged to guess or pass on words found to be difficult. The first chart was randomly selected and then the two versions were used alternately for each lamp. Lamps were used in a random order to reduce the possibility of confounding the results through learning or fatigue effects. Reading distance was regularly checked to be $40 \mathrm{~cm}$ during each testing session using a tape measure. Standard clinical practice is to recommend that lamps are shone from over the patient's shoulder, however, we were concerned that the subject's body could shadow the task so positioned each lamp above the MNRead card, in front of, but shielded from the subjects face and adjusted accordingly to reduce the possibility of creating disability or discomfort glare (Collins, 1987b; Bowers et al., 2001). Testing took place in a dark room with no ambient illumination and subjects were light adapted for 5 min with each source.

\section{AMD classification}

Standard colour $50^{\circ}$ photographs taken from the study eye of each subject were evaluated for drusen, retinal hyperpigmentation and hypopigmentation, and geographic atrophy/dry age-related atrophy using a procedure described by Haymes and Lee (2006) and the International Classification and grading System for Age-related 
Maculopathy and Age-related Macular Degeneration (Bird et al., 1995). Based on this evaluation subjects were divided into two groups: age-related maculopathy (ARM) or non-exudative AMD.

\section{Data analysis}

All test sessions were tape-recorded. The time taken to read each sentence was divided into 60 and the result multiplied by the total number of words read correctly for each print size to give oral reading rate in terms of correct words per minute for each print size. For example, a participant that read 12 words in one sentence correctly in 20 seconds would have an oral reading rate of 36 correct words per minute $(60 / 20 \times 12)$. Oral reading rate was plotted against print size and CPS was determined by eye, fitting a smooth curve to the data and selecting the smallest print size for maximum reading rate. Threshold print size and AR and MRR were also calculated.

\section{Statistical analysis}

Statistical analysis of data was carried out using StatSoft, Inc. (2001), STATISTICA (data analysis software system), version 6 (www.statsoft.com).

\section{Results}

\section{Subject characteristics}

Individual subject characteristics are presented in table 2.

\section{Reading performance}

Mean reading rate was normally distributed (Kolmogorov-Smirnov $p>0.05$ ) while TPS, CPS and AR were not normally distributed (Kolmogorov-Smirnov $p<0.05$ ) so non-parametric techniques were used in the analyses of these three outcome measures. We were interested in a $p$ value less than or equal to 0.05 . There were no statistically significant interactions between the type of AMD and spectral radiance for any of the measures of reading performance $(p>0.05)$. Analysis of MRR data using a one-way ANOVA showed that there was no statistically significant difference between the lamps $(p=0.78)$ and a Kruskal-Wallis ANOVA showed that there was no statistically significant difference for any of the other reading outcome measures; TPS $p=0.67, C P S p=$ 0.74 and $\mathrm{AR} \mathrm{p}=0.84$. Mean $\mathrm{AR}$ in log units for each lamp was calculated as $\mathrm{SI}=0.12, \mathrm{DI}=0.16, \mathrm{CF}=0.22, \mathrm{HI}$ $=0.17$, Individual subject and lamp data are presented in table 3 .

\section{Discussion}

No statistically significant difference was found for reading performance outcome measures between any of the lamps investigated in this study for subjects with ARM or non-exudative AMD and we found no statistically significant interaction between AMD classification and spectral radiance. Furthermore, the mean AR obtained for each lamp and the majority of the individual subject AR values are below the level found to be necessary for fluent reading (0.30 log units) with low vision (Whitaker and Lovie-Kitchin, 1993; Cheong et al., 2002).. In other words, with a lamp producing 2000 lux in the plane of the task, most subjects in this study would require less 
magnification to move from threshold to fluent reading performance than expected from the findings of other studies in this area .

Our finding that the spectral radiance of lamps commonly used in low vision rehabilitation has no effect on reading for subjects with ARM and non-exudative AMD agrees well with the only other study to investigate this relationship for subjects with AMD (Haymes and Lee, 2006). Furthermore, Legge and Rubin (1986) using text of various colours displayed on a TV monitor also found that reading, along with VA and CS, was not wavelength dependent for subjects with central field loss. A statistically significant improvement in CS with daylight simulation incandescent lamps has been reported but this was not considered to be of clinical significance (Cohen and Rosenthal, 1988; Haymes and Lee, 2006). Interestingly, Lindner et al. (1989) found that subjects with cataract or glaucoma required 30 to $35 \%$ more illuminance when reading with a daylight simulation fluorescent light compared to warm white or white fluorescent light although no spectral radiance data was included in their report.

Abramov and Gordon (1977) proposed that people without ocular disease read better with blue-light when using the peripheral retina while Haymes and Lee (2006) postulated that the slight increase in CS with a daylight simulation incandescent lamp for their group with AMD could be due to peripheral retinal effects. This does not seem to be the case for our subjects with ARM and non-exudative AMD. Even though it is very likely that peripheral retina was being used - at least by those with AMD, the daylight incandescent lamp (a source producing relatively more blue light) did not affect reading. The reasons why daylight simulation incandescent lamps result in better CS but have no effect on reading in AMD are unclear. The lack of any significant difference between the lamps used in this study does not suggest that there is a relationship between spectral radiance and retinal scatter.

Several limitations of the study are acknowledged. The subject group was small, all participants had ARM or moderate non-exudative AMD and some subjects had good VA. However, when the findings from this study are combined with those of Haymes and Lee (2006) who used similar lamps but subjects with more varied AMD (including the exudative form) and poorer VA, the range of people for whom the spectral radiance of localised lighting is unlikely to be of any clinical importance is extended.

In future studies, it may be better to determine the optimum illuminance for each participant and then to carry out spectral radiance investigations at this optimum level. Also, it may be advantageous to include subjects with exudative AMD and lens opacities where disability glare may be induced by high illuminance levels.

\section{Conclusion}

This study adds further support to the body of evidence, which suggests that, for people with ARM and nonexudative AMD, the spectral radiance of localised light sources is not an important factor when deciding on the type of lamp to use for reading. 


\section{References}

Abramov, I. and Gordon, J. (1977) Color vision in the peripheral retina. I. Spectral sensitivity. J Opt Soc Am. 67, 195-202.

Ahn, S. J., Legge, G. E. and Luebker, A. (1995) Printed cards for measuring low-vision reading speed. Vision Res. 35, 1939-44.

Bailey, I. L. and Lovie, J. E. (1976) New design principles for visual acuity letter charts. Am J Optom Physiol Opt. 53, 740-5.

Bartlett, H. and Eperjesi, F. (2003) A randomised controlled trial investigating the effect of nutritional supplementation on visual function in normal, and age-related macular disease affected eyes: design and methodology [ISRCTN78467674]. Nutr. J. 2, 12.

Bird, A. C., Bressler, N. M., Bressler, S. B., Chisholm, I. H., Coscas, G., Davis, M. D., de Jong P. T., Klaver, C. C., Klein, B. E., Klein, R., Mitchell P., Sarks, J. P., Sarks, J. H., Soubrane, G., Taylor, H. R. and Vingerling, J. R. (1995) An international classification and grading system for age-related maculopathy and age-related macular degeneration. The International ARM Epidemiological Study Group. Surv Ophthalmol. 39, 367-74.

Brown B, Kitchin JL. (1983) Dark adaptation and the acuity/luminance response in senile macular degeneration (SMD). Am J Optom Physiol Opt. 60, 645-50.

Bowers, A. R., Meek, C. and Stewart, N. (2001) Illumination and reading performance in age-related macular degeneration. Clin Exp Optom. 84, 139-147.

Cheong, A. C., Lovie-Kitchin, J. E. and Bowers, A. R. (2002) Determining magnification for reading with low vision. Clin Exp Optom. 85, 229-37.

Chylack, L. T. Jr, Leske, M. C., Sperduto, R., Khu, P. and McCarthy, D. (1988) Lens Opacities Classification System. Arch Ophthalmol. 106, 330-4.

Cohen, J.M. and Rosenthal, B.P. (1988) An evaluation of an incandescent neodymium light source on near point performance of a low vision population. J. Vision Rehabil. 2, 15-21.

Collins, J. (1987a) The evaluation of three types of light source. Lighting publication. Partially Sighted Society, Doncaster, UK. 
Collins, J. (1987b) Non-optical low vision aids. Optician 15 May, 32-33.

Cullinan, T.R., Silver, J.H., Gould, E. S. and Irvine, D. (1979) Visual disability and home lighting. Lancet 8117, 642-4.

De l'Aune, W.R., Welsh, R.L. and Williams, M.D. (2000) Outcome assessment of the rehabilitation of people with visual impairment: a naproject in the United States. J Vis Imp Blind. 95, 281-91.

Elliott, D.B., Trukolo-llic, M., Strong, J.G., Pace, R., Plotkin, A. and Bevers, P. (1997) Demographic characteristics of the vision-disabled elderly. Invest Ophthalmol Vis Sci. 38, 2566-75.

Eldred, K. B. (1992) Optimal illumination for reading in patients with age-related maculopathy. Optom Vis Sci. 69, 46-50.

Evans, J. Causes of Blindness and Partial Sight in England and Wales 1990-1991. Studies on Medical and Population Subjects No. 57. London 1995, HMSO.

Fonda, G. Management of low vision. New York: Thieme-Stratton, 1981; pp 178-179.

Fosse, P. and Valberg, A. (2004) Lighting needs and lighting comfort during reading with age-related macular degeneration. J Vis Impair Blind. 98, 1-23.

Gill, J. M. and Silver, J. H. (1982) Illumination from domestic lamps. The Ophthalmic Optician. April 24, 282.

Kitchin, J. E. (1981) Assessment of visual functions of patients with senile macular degeneration. Aust J Optom. 64, 176-183.

Haymes SA, Lee J. (2006) Effects of task lighting on visual function in age-related macular degeneration. Ophthalmic Physiol Opt. 26, 169-79.

Hazel, C. A., Petre K. L., Armstrong, R. A., Benson, M. T. and Frost, N. A. (2000) Visual function and subjective quality of life compared in subjects with acquired macular disease. Invest Ophthalmol Vis Sci. 41, 1309-15.

Julian, W. G. (1984) Variation in near visual acuity with illuminance for a group of 27 partially sighted people. Lighting Research and Technology. 16, 34-41. 
Lagrow, S. J. (1986) Assessing optimal illumination for the visual response accuracy in visually impaired adults. $\mathrm{J}$ Vis Impair Blind. 83, 888-895.

Legge, G.E. and Rubin, G.S. Psychophysics of reading. IV. (1986) Wavelength effects in normal and low vision. J Opt Soc Am A. 3, 40-51.

Legge, G.E., Ross, J.A., Luebker, A. and LaMay, J.M. (1989) Psychophysics of reading. VIII. The Minnesota Low-Vision Reading Test. Optom Vis Sci. 66, 843-53.

Lindner, H., Hubner, K., Scholte, H. and Rohl, F. (1989) Subjective lighting needs of the old and pathological eye. Lighting Res. Technol. 21, 1-10.

Mangione, C.M., Berry, S., Spritzer, K., Janz, N. K., Klein, R., Owsley, C. and Lee, P.P. (1998) Identifying the content area for the 51-item National Eye Institute Visual Function Questionnaire: results from focus groups with visually impaired persons. Arch Ophthalmol. 116, 227-33.

Mehr, E.B. and Freid, A. N. Low vision care. Chicago: Professional Press, 1975.

Silver, J. H., Gould, E. S., Irvine, D. and Cullinan, T. R. (1978) Visual acuity at home and in eye clinics. Trans Opthal Soc UK 98, 262-266.

Sloan, L. L. (1969) Variation of acuity with luminance in ocular disease and anomalies. Doc Ophthalmol. 26, 384393.

Soldatova, A. M. (1990) Retinal function under conditions of artificial illumination with varying spectral makeup in patients with sclerotic macular dystrophy. Oftalmol Zh. 7, 403-8.

Whitaker, D., Steen, R.and Elliott, D. B. (1993) Light scatter in the normal young, elderly, and cataractous eye demonstrates little wavelength dependency. Optom Vis Sci. 70, 963-8.

Whittaker, S. G. and Lovie-Kitchin J. (1993) Visual requirements for reading. Optom Vis Sci. 70, 54-65.

Table 1. Lamp features

\begin{tabular}{|l|l|l|l|l|}
\hline Lamp & Manufacturer & Wattage & $\begin{array}{l}\text { Correlated colour } \\
\text { temperature (K)* }\end{array}$ & $\begin{array}{l}\text { Chromatic } \\
\text { coordinate }\end{array}$ \\
\hline Clear tungsten incandescent & Osram & 60 & 2692 & $0.46,0.41$ \\
\hline Daylight simulation (blue tint) incandescent tungsten & GE & 60 & 3378 & $0.42,0.40$ \\
\hline
\end{tabular}




\begin{tabular}{|l|l|l|l|l|}
\hline Compact cool white fluorescent & Osram & 11 & 3923 & $0.38,0.38$ \\
\hline Halogen tungsten & Unknown & $20 \mathrm{~W}$ & 2866 & $0.44,0.40$ \\
\hline
\end{tabular}

${ }^{*}$ Correlated colour temperature and chromaticity coordinates for a 2-degree observer

Table 2. Individual subject characteristics

\begin{tabular}{|c|c|c|c|c|c|}
\hline Subject & $\begin{array}{l}\text { Age } \\
\text { (yrs) }\end{array}$ & $\begin{array}{c}\text { Distance logMAR } \\
\text { VA }\end{array}$ & $\begin{array}{c}\text { Near logMAR } \\
\text { VA }\end{array}$ & $\log C S$ & ARM/non-exudative AMD \\
\hline 1 & 76 & 0.12 & 0.06 & 1.00 & ARM \\
\hline 2 & 56 & 0.20 & 0.3 & 1.35 & AMD \\
\hline 3 & 70 & 0.58 & 0.4 & 1.35 & AMD \\
\hline 4 & 80 & 0.20 & 0.1 & 1.35 & AMD \\
\hline 5 & 82 & 0.20 & 0.3 & 1.35 & AMD \\
\hline 6 & 55 & 0.10 & 0.2 & 1.65 & ARM \\
\hline 7 & 72 & 0.24 & 0.1 & 0.65 & AMD \\
\hline 8 & 72 & 0.10 & 0.32 & 1.20 & ARM \\
\hline 9 & 61 & 0.10 & 0.2 & 1.45 & ARM \\
\hline 10 & 73 & 0.10 & 0.2 & 1.20 & ARM \\
\hline 11 & 65 & 0.04 & 0.1 & 1.65 & ARM \\
\hline 12 & 72 & 0.72 & 0.8 & 1.5 & AMD \\
\hline 13 & 68 & 0.68 & 0.1 & 1.35 & AMD \\
\hline Mean & 69 & 0.26 & 0.24 & 1.18 & ARM, $n=6$ \\
\hline SD & 8 & 0.24 & 0.20 & 0.18 & AMD, $n=7$ \\
\hline
\end{tabular}

VA visual acuity, CS contrast sensitivity, ARM age-related maculopathy, AMD age-related macular degeneration 
Table 3 Individual subject and lamp data

\begin{tabular}{|c|c|c|c|c|c|c|c|c|c|l|c|c|c|c|c|c|c|c|c|}
\hline Lamp & \multicolumn{3}{|c|}{ SI } & \multicolumn{3}{|c|}{ DI } & & \multicolumn{3}{|c|}{ CF } & \multicolumn{3}{c|}{ HI } \\
\hline Subject & TPS & CPS & AR & MRR & & TPS & CPS & AR & MRR & & TPS & CPS & AR & MRR & & TPS & CPS & AR & MRR \\
\hline 1 & 0.30 & 0.40 & 0.10 & 214 & & 0.31 & 0.60 & 0.29 & 194 & & 0.30 & 0.40 & 0.10 & 174 & & 0.30 & 0.40 & 0.10 & 154 \\
\hline 2 & 0.00 & 0.20 & 0.20 & 207 & & 0.01 & 0.10 & 0.09 & 171 & & 0.01 & 0.20 & 0.19 & 194 & & 0.01 & 0.20 & 0.19 & 188 \\
\hline 3 & 0.56 & 0.60 & 0.04 & 162 & & 0.59 & 0.80 & 0.21 & 100 & & 0.56 & 0.80 & 0.24 & 167 & & 0.57 & 0.60 & 0.03 & 171 \\
\hline 4 & 0.34 & 0.40 & 0.06 & 182 & & 0.30 & 0.60 & 0.30 & 273 & & 0.30 & 0.40 & 0.10 & 286 & & 0.30 & 0.40 & 0.10 & 214 \\
\hline 5 & 0.49 & 0.60 & 0.11 & 133 & & 0.40 & 0.50 & 0.10 & 115 & & 0.37 & 0.40 & 0.03 & 146 & & 0.40 & 0.70 & 0.30 & 118 \\
\hline 6 & 0.08 & 0.20 & 0.12 & 214 & & 0.11 & 0.40 & 0.29 & 188 & & 0.01 & 0.30 & 0.29 & 188 & & 0.01 & 0.50 & 0.49 & 167 \\
\hline 7 & 0.40 & 0.60 & 0.20 & 162 & & 0.50 & 0.60 & 0.10 & 158 & & 0.40 & 0.70 & 0.30 & 167 & & 0.60 & 0.60 & 0.00 & 194 \\
\hline 8 & 0.50 & 0.60 & 0.10 & 140 & & 0.50 & 0.70 & 0.20 & 133 & & 0.50 & 0.60 & 0.10 & 150 & & 0.50 & 0.60 & 0.10 & 162 \\
\hline 9 & 0.30 & 0.40 & 0.10 & 240 & & 0.35 & 0.40 & 0.05 & 231 & & 0.30 & 0.60 & 0.30 & 250 & & 0.22 & 0.30 & 0.08 & 167 \\
\hline 10 & 0.10 & 0.20 & 0.10 & 300 & & 0.18 & 0.20 & 0.02 & 300 & & 0.03 & 0.20 & 0.17 & 200 & & 0.13 & 0.30 & 0.17 & 250 \\
\hline 11 & 0.10 & 0.20 & 0.10 & 220 & & 0.10 & 0.30 & 0.20 & 197 & & 0.10 & 0.20 & 0.10 & 246 & & 0.10 & 0.20 & 0.10 & 168 \\
\hline 12 & 0.61 & 0.90 & 0.29 & 200 & & 0.65 & 0.80 & 0.15 & 190 & & 0.08 & 0.90 & 0.82 & 190 & & 0.62 & 0.90 & 0.28 & 185 \\
\hline 13 & 0.30 & 0.40 & 0.10 & 204 & & 0.30 & 0.40 & 0.10 & 238 & & 0.30 & 0.40 & 0.10 & 214 & & 0.30 & 0.60 & 0.30 & 240 \\
\hline & & & & & & & & & & & & & & & & & & \\
\hline Mean & 0.31 & 0.44 & 0.12 & 198 & & 0.33 & 0.49 & 0.16 & 191 & & 0.25 & 0.47 & 0.22 & 198 & & 0.31 & 0.48 & 0.17 & 183 \\
\hline SD & 0.20 & 0.21 & 0.07 & 44 & & 0.20 & 0.22 & 0.09 & 59 & & 0.19 & 0.23 & 0.20 & 42 & & 0.22 & 0.21 & 0.14 & 36 \\
\hline
\end{tabular}

Lamps-SI standard incandescent, DI daylight simulation incandescent, CF compact fluorescent, $\mathrm{HI}$ halogen incandescent. Reading outcome measures-TPS threshold print size logMAR, CPS critical print size logMAR, AR acuity reserve, MRR maximum reading rate as correct words per minute. 
Figure 1. Measured spectral radiance curves for study lamps

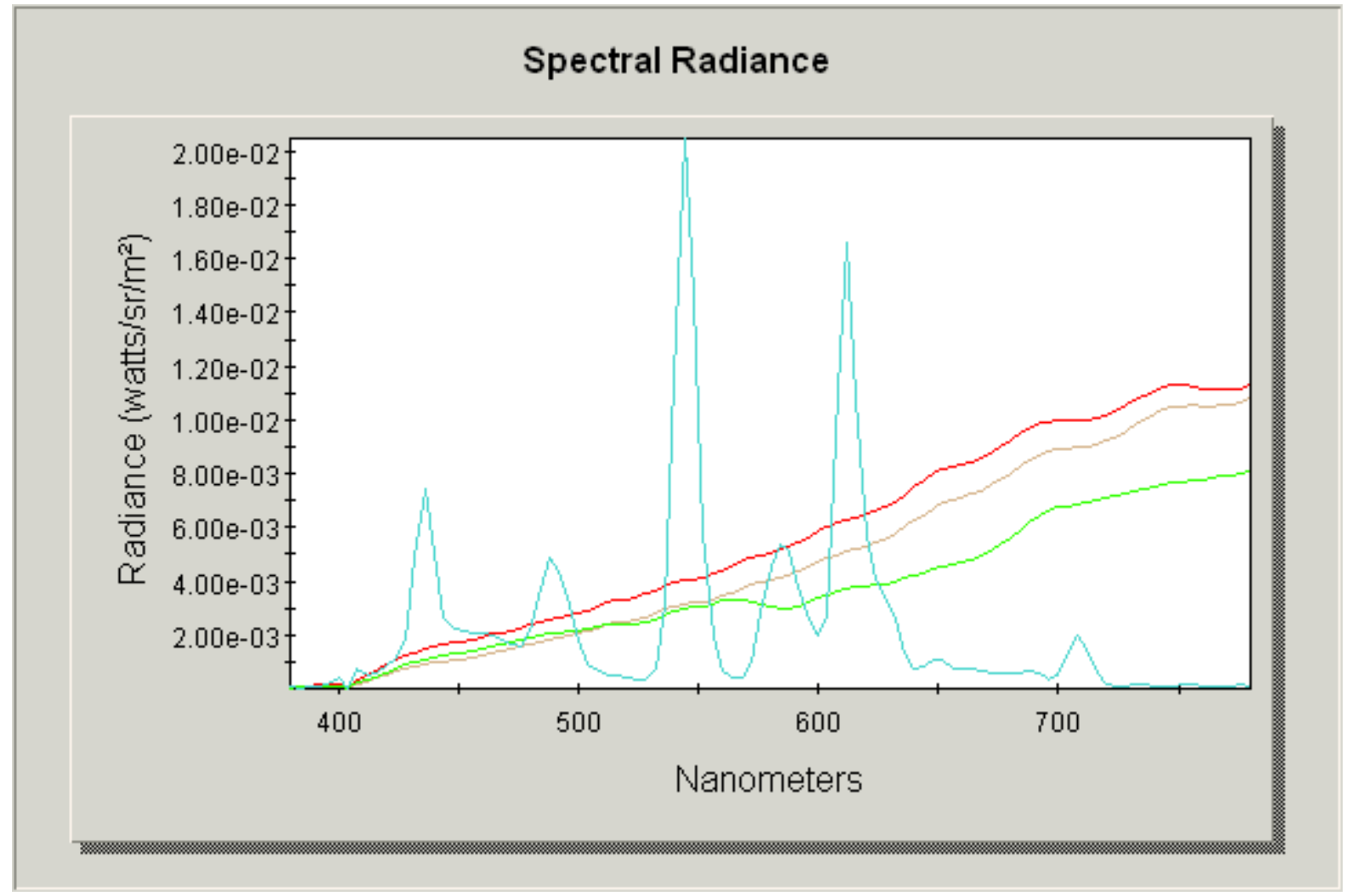

Standard incandescent (SI - brown) daylight simulation incandescent (DI - green), compact fluorescent (CF blue) and halogen incandescent ( $\mathrm{HI}$ - red) lamps. Measurements made at 2000 lux for each lamp. 